\title{
Increased Reactive Oxygen Species Production by Alveolar Macrophages from Malignant Lobe of Lung Cancer Patients
}

\author{
Rashmi N. Sharma, ${ }^{1}$ Digamber Behera,${ }^{2}$ and Krishan L. Khanduja ${ }^{1, *}$ \\ ${ }^{1}$ Department of Biophysics and ${ }^{2}$ Department of Pulmonary Medicine, Postgraduate \\ Institute of Medical Education and Research, Chandigarh 160 012, India
}

(Received March 17, 1997)

\begin{abstract}
Summary Alveolar macrophages (AMs) may contribute to inflammation in multiple ways, including the release of reactive oxygen species (ROS) such as superoxide anion $\left(\mathrm{O}_{2}^{-}\right)$and hydrogen peroxide $\left(\mathrm{H}_{2} \mathrm{O}_{2}\right)$. This provides a basis for a plausible and testable hypothesis by which inflammation and the disease might be related; that is, the levels of ROS generated by inflammatory phagocytes might be dependent upon the type of disease. Alveolar macrophages were prepared from 25 lung cancer patients, $58.7 \pm 7.51$ years of age (mean $\pm S D$ ). Alveolar macrophages from 12 patients, $45.3 \pm 14.6$ years of age, with nonmalignant lung diseases were also studied. Production of oxygen radical species was higher in AMs from the malignant lobe of lung cancer patients than in those from the disease-free lobe. However, the levels in AMs from the diseasefree lobe were comparable to the levels in AMs from patients with nonmalignant lung diseases. There was an increase in hydrogen peroxide formation in the cells from malignant lobe of lung cancer patients compared with that in those from the disease-free lobe $(38.4 \pm 4.16$ vs. $26.9 \pm 2.94 \mathrm{nmol} / \mathrm{mg}$ ). The formation in the cells from patients with nonmalignant lung diseases was found to be $18.0 \pm 1.19 \mathrm{nmol} / \mathrm{mg}$ protein. In the presence of phorbol-12-myristate-13-acetate, the formation in the cells from malignant lobe of lung cancer patients increased compared with that from the disease-free lobe $(63.9 \pm 7.65$ vs. $34.3 \pm 4.95 \mathrm{nmol} / \mathrm{mg}$ protein), and the formation in the cells from patients with nonmalignant lung diseases was $42.5 \pm 5.03 \mathrm{nmol} / \mathrm{mg}$ protein. The enormous increase in $\mathrm{O}_{2}{ }^{-}$and $\mathrm{H}_{2} \mathrm{O}_{2}$ production in malignancy needs further investigation for its diagnostic and prognostic values.
\end{abstract}

Key Words: Alveolar macrophages, superoxide anion, hydrogen perox-

\footnotetext{
${ }^{*}$ To whom correspondence should be addressed.
} 
ide, lung cancer, bronchoalveolar lavage

Cancer of the lung is the most frequent cancer-related cause of death in both males and females throughout the world. The lungs are unique in having an epithelial surface area that is also at risk of oxidant-mediated attack by environmental factors including cigarette smoke [1] and activated phagocytes.

Macrophages are capable of secreting a variety of cytokines. In general, normal alveolar macrophages (AMs) do not constitutively secrete significant levels of anabolic cytokines. With stimulation either in vivo or in vitro they produce a variety of cytokines. Cytokines such as tumor necrosis factor, interleukins (IL-1, IL-2), interferon (IFn) released by activated macrophages and lymphocytes, and soluble inflammatory mediators released by neutrophils into the site of injury including the lungs amplify and perpetuate inflammation [2]. The macrophages, once activated, are also capable of releasing toxic oxygen intermediates such as superoxide anion radical $\left(\mathrm{O}_{2}{ }^{-}\right)$, hydrogen peroxide $\left(\mathrm{H}_{2} \mathrm{O}_{2}\right)$, and hydroxyl radical $(\cdot \mathrm{OH})$.

Recently, several authors have demonstrated that oxygen metabolites produced by inflammatory cells are capable of causing injury to various cells and tissues both in vivo and in vitro [3-7]. Besides this, investigators have found that AMs from cigarette smokers release more oxygen radical species in vitro than do AMs from non-smokers $[8,9]$. Oxygen radicals derived from these cells can induce DNA damage [10] and cause transformation of cells in culture [11], suggesting that active oxygen production by phagocytic cells may play a role in tumor promotion. The tumor-promoting phorbol esters such as phorbol-12-myristate-13acetate (PMA) have been shown to stimulate the production of oxygen radicals by neutrophils $[12,13]$ and macrophages [14-16] following in vitro treatment. In the present study, we have evaluated the status of $\mathrm{O}_{2}{ }^{-}$and $\mathrm{H}_{2} \mathrm{O}_{2}$ in alveolar macrophages of lung cancer patients. The AMs were collected from the malignant and disease-free lobe separately for their comparison with other nonmalignant lung diseases.

\section{MATERIALS AND METHODS}

Twenty-five histologically proven lung malignancy patients recruited from the Pulmonary Medicine Unit at Nehru Hospital, PGIMER, were studied as outlined in Table 1. Out of these patients, twenty-two were smokers and three were nonsmokers. Of the smokers, two of them had smoked only hukka for a period of more than 25 years; and the rest were smoking either beedi and/or cigarettes. All three non-smokers were females. Nineteen of the smokers were heavy smokers (smoking index: $>300$ or hukka smoking $>25$ years) and three were moderate ones (smoking index: 101-300). The smoking index was defined as the No. of cigarettes and/ or beedi smoked per day $\times$ duration of smoking in years.

Twelve patients with nonmalignant lung diseases were also enrolled in the 
Table 1. Characteristics of the study subjects.

\begin{tabular}{|c|c|c|c|}
\hline & \multicolumn{2}{|c|}{ Lung cancer subjects } & \multirow{2}{*}{$\begin{array}{l}\text { Nonmalignant } \\
\text { lung disease } \\
\quad(n=12)\end{array}$} \\
\hline & $\begin{array}{l}\text { Disease-free lobe } \\
\qquad(n=25)\end{array}$ & $\begin{array}{l}\text { Malignant lobe } \\
\quad(n=25)\end{array}$ & \\
\hline Sex, M/F & $21 / 4$ & $21 / 4$ & $8 / 4$ \\
\hline Age, year & $58.7 \pm 7.51$ & $58.7 \pm 7.51$ & $45.3 \pm 14.6$ \\
\hline Bronchoalveolar lavage recovery (\%) & $50.5 \pm 11.9$ & $40.6 \pm 7.66^{* *}$ & $44.0 \pm 16.4$ \\
\hline Alveolar macrophages $\left(\times 10^{6}\right.$ cells $)$ & $3.22 \pm 0.73$ & $4.97 \pm 0.80^{* *}$ & $3.90 \pm 0.75^{*}$ \\
\hline
\end{tabular}

Values are expressed as the mean \pm SD. ${ }^{* *} p<0.001$ vs. disease-free lobe; ${ }^{*} p<0.05$ vs. diseasefree lobe.

study. Of these patients three had hemoptysis, and there was one for each of the following disorders: bronchopneumonia, tuberculosis, lung inflammation, chronic obstructive pulmonary disease, transbronchial, silicosis, and sarcoidosis. The remaining two patients had normal study. Subjects with lower respiratory infection in the preceding 4 weeks were excluded from the study. Similarly those who had received specific therapy for lung malignancy, in the form of chemotherapy and/or radiotherapy were also excluded from the study.

All the subjects gave their informed consent for the procedure and the study fulfilled the criteria of the Ethical Committee of our hospital.

Chemicals. Stock solutions of PMA were made in dimethyl sulphoxide to a concentration of $1 \mu \mathrm{g} / \mathrm{ml}$ and stored at $0^{\circ} \mathrm{C}$. Earle's balanced salt solution, horseradish peroxidase (HRPO), nitroblue tetrazolium (NBT), and superoxide dismutase (SOD) were obtained from Sigma Chemical Co. (St. Louis, MO).

Bronchoscopy with bronchoalveolar lavage. Each subject in the study underwent a fiberoptic bronchoscopy after an overnight fast. Premedication for the bronchoscopy was done with Inj Phenergan, $25 \mathrm{mg}$ I.M., and Inj Atropine, $0.6 \mathrm{mg}$ I.M., administered one-half hour before the procedure. Local anesthetic (2\% xylocaine) was given through a nebulizer just before the procedure. The fiberoptic bronchoscope was passed transnasally. Segmental lavage was performed by injecting 10-ml aliquots of sterile physiological saline solution to a total volume of 50 $\mathrm{ml}$. Similar lavage was performed from the healthy segment of the opposite normal lung, that is, from a disease-free lobe.

The bronchoalveolar lavage (BAL) fluid recovered was collected in $61 \mathrm{~mm}$ diameter, 250-ml capacity polypropylene autoclaved containers. The amount of BAL fluid retrieved was noted. The BAL fluid was immediately filtered through sterile coarse surgical gauze and centrifuged at $500 \times \mathrm{g}$ for $15 \mathrm{~min}$ at $4^{\circ} \mathrm{C}$. The cells were washed with cold Earle's balanced salt solution. Cell viability was estimated by exclusion of trypan blue. The number of cells was measured with a hemocytometer.

Determination of superoxide production. The procedure used to assess superoxide anion radical production by AMs was a modification of that originally described by Park et al. [17]. This method is based on the fact that nitroblue 
tetrazolium (NBT) in the presence of superoxide anion radical is reduced to an insoluble cytoplasmic blue formazan precipitate, which can be visualized by light microscopy. $1 \times 10^{6}$ AMs in $0.1 \mathrm{ml}$ of HBSS and $0.35 \mathrm{ml}$ NBT solution $(0.5 \%$ NBT in PBS) were added to culture dishes and incubated at $37^{\circ} \mathrm{C}$ in $5 \% \mathrm{CO}_{2}$ for $1 \mathrm{~h}$, with or without $0.05 \mathrm{ml}$ phorbol myristate acetate (PMA $\mu \mathrm{g} / \mathrm{ml}$ ). In all assays a test sample was treated with SOD $(0.25 \mathrm{mg} / \mathrm{ml})$ during the in vitro NBT treatment to assess the superoxide anion radical-specific reduction of NBT. All results were expressed as the number of formazan-positive AMs/250 AMs.

Estimation of hydrogen peroxide. The amount of $\mathrm{H}_{2} \mathrm{O}_{2}$ released by AMs with and without PMA stimulation was estimated by the horseradish peroxidase method [18]. To the AMs, $1.0 \mathrm{ml}$ of phenol red solution (1\%) was added, and incubation was then conducted at $37^{\circ} \mathrm{C}$ for $30 \mathrm{~min}$ with or without $1 \mu \mathrm{g} / \mathrm{ml}$ of PMA. Optical density readings were taken at $610 \mathrm{~nm}$ after making the assay mixture alkaline by adding $10 \mu 1$ of $1 \mathrm{~N} \mathrm{NaOH}$. The amount of cell protein was determined by covering the monolayers with $1 \mathrm{ml}$ of $1 \mathrm{~N} \mathrm{NaOH}$ and allowing them to stand overnight at $37^{\circ} \mathrm{C}$ and then assaying the protein content of the digest by the method of Lowry et al. [19].

\section{RESULTS}

\section{Total cell counts and BAL volume return}

Total cell counts and BAL volume return are shown in Table 1. There was a significant difference between the percentage of fluid recovered from the malignant lobe and that recovered from disease-free lobe of lung cancer patients $(40.6 \pm 7.66$ vs. $50.5 \pm 11.9, p<0.001)$. There also was a significant difference between the AMs from malignant lobe or nonmalignant lung diseases and that obtained from the disease-free lobe $\left(\times 10^{6}\right.$ cells $)(4.97 \pm 0.80,3.90 \pm 0.75$ vs. $3.22 \pm 0.73)$.

Effect of PMA on superoxide anion release by AMs from malignant and disease-free lobe of the lung cancer patients

The effect of different concentrations of PMA $(0.01,0.1$, and $1 \mu \mathrm{g} / \mathrm{ml})$ was examined to find the maximum effective dose for optimum induction of superoxide anion radicals. Figure 1 shows that $0.1 \mu \mathrm{g} P M A / m l$ was sufficient to induce maximum production of $\mathrm{O}_{2}^{-}$. The number of formazan-positive cells per $250 \mathrm{AMs}$ in the absence of PMA in the disease-free lobe was $1.60 \pm 0.54$; and in the malignant lobe it was $4.60 \pm 0.89$. When AMs were treated in vitro with PMA, the number of formazan-positive cells in the disease-free lobe was $1.80 \pm 0.44,5.60 \pm$ 1.40 , and $6.80 \pm 1.09$ at $0.01,0.1$, and $1 \mu \mathrm{g} / \mathrm{ml}$ concentrations. The number of formazan-positive cells in the malignant lobe was $6.20 \pm 1.09,17.4 \pm 1.72$, and $19.2 \pm 1.64$ at $0.01,0.1$, and $1 \mu \mathrm{g} / \mathrm{ml}$ concentrations, respectively. 


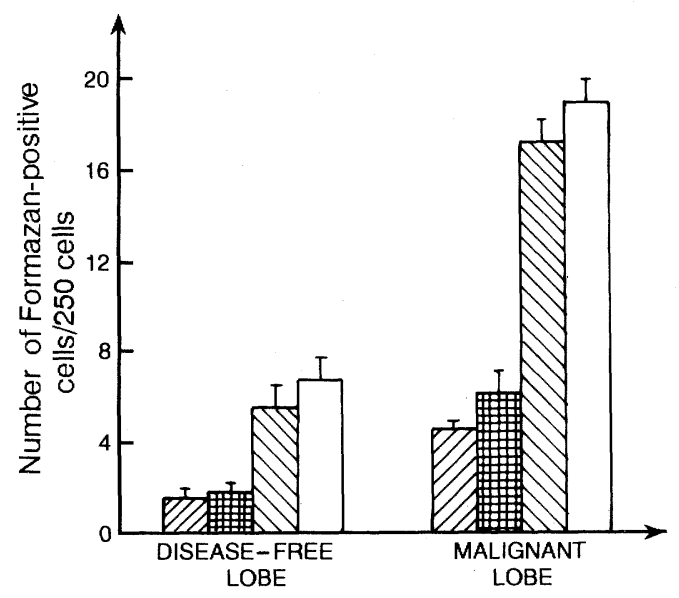

Fig. 1. Optimum dose of PMA required to induce maximum in vitro formation of superoxide anion radicals by human AMs. Disease free lobe, $n=5$; malignant lobe, $n=5$. Dose

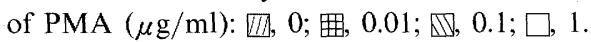

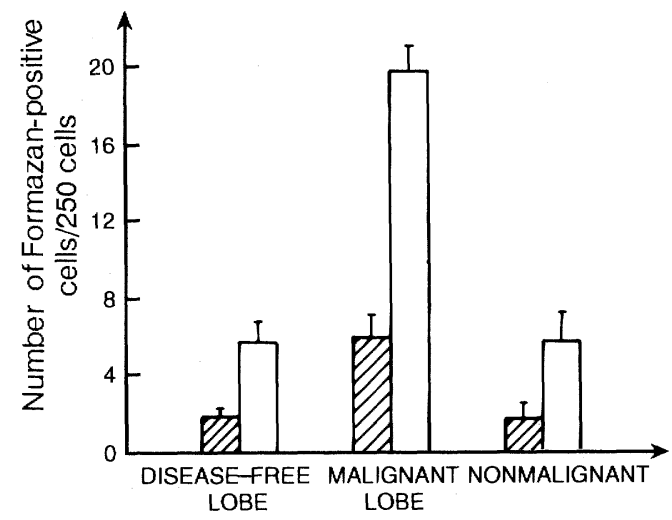

Fig. 2. Comparison of the production of $\mathrm{O}_{2}-$ by alveolar macrophages from malignant and disease-free lobes of lung cancer patients and from patients with nonmalignant lung diseases. Disease-free lobe, $n=25$; malignant lobe, $n=25$; nonmalignant lobe, $n=12$. Dose of PMA $(\mu \mathrm{g} / \mathrm{ml}): \mathbb{U}, 0 ; \square, 1$.

Superoxide anion radical production by AMs from lung cancer patients and patients with nonmalignant lung diseases treated in vitro with PMA

Figure 2 shows the comparison of the in vitro production of $\mathrm{O}_{2}{ }^{-}$by PMAtreated AMs from malignant and disease-free lobes of lung cancer patients and nonmalignant lung diseases. The results indicated a significant increase in superoxide anion formation from $5.80 \pm 1.77$ to $19.5 \pm 3.36$ in the malignant lobe. However, 


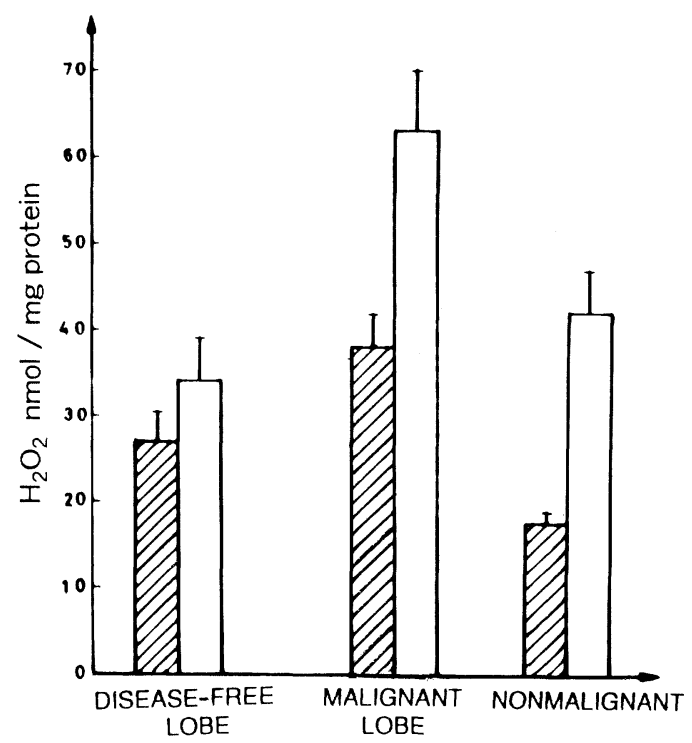

Fig. 3. Production of $\mathrm{H}_{2} \mathrm{O}_{2}$ by alveolar macrophages from malignant and disease-free lobes of lung cancer patients and from patients with nonmalignant lung diseases. Disease-free lobe, $n=25$; malignant lobe, $n=25$; nonmalignant lobe, $n=12$. Dose of PMA $(\mu \mathrm{g} / \mathrm{ml})$ : $\square, 0 ; \square, 1$.

in the disease-free lobe it was increased from $1.80 \pm 0.79$ to only $5.80 \pm 1.12$. This increase was comparable to that in the level for nonmalignant lung diseases, that is, from $1.80 \pm 1.08$ to $5.80 \pm 1.56$.

Hydrogen peroxide production by AMs from lung cancer patients and patients with nonmalignant lung diseases

Figure 3 compares the in vitro production of $\mathrm{H}_{2} \mathrm{O}_{2}$ by PMA-treated AMs from malignant and disease-free lobes of lung cancer patients and nonmalignant lung diseases. There was an increase in hydrogen peroxide formation from $38.4 \pm 4.16$ to $63.9 \pm 7.65 \mathrm{nmol} / \mathrm{mg}$ in the malignant lobe. However, in the disease-free lobe it was increased from $26.9 \pm 2.94$ to only $34.3 \pm 4.95 \mathrm{nmol} / \mathrm{mg}$; and in nonmalignant lung diseases the increase was from $18.0 \pm 1.19$ to $42.5 \pm 5.03 \mathrm{nmol} / \mathrm{mg}$ protein.

\section{DISCUSSION}

In the present study, $88 \%$ of the patients were smokers, which was no surprise. Tobacco smoking continues to be the single most important etiological factor for lung cancer in the Indian population. Various studies in the past have addressed various aspects of alveolar macrophage function and have resulted in contradictory views on their role in lung cancer patients.

Numerous studies, including the present one, have demonstrated that in vitro 
treatment of neutrophils $[20,21]$ and macrophages [22, 23] with tumor promoters results in the production of superoxide anion radicals. PMA is a well-known activator of protein kinase $\mathrm{C}[24,25]$, and presumably replaces diacylglycerol, the endogenous activator of protein kinase $\mathrm{C}$, in binding to and activating this kinase $[24,26]$. The activation of protein kinase $\mathrm{C}$ results in the stimulation of a respiratory burst in inflammatory cells $[27,28]$; however, the activation of protein kinase $\mathrm{C}$ may not be the only mechanism by which oxygen radical production can be stimulated in these cells $[29,30]$.

Chemiluminescence of pulmonary alveolar macrophages from bronchogenic carcinoma patients was demonstrated by Weissler et al. [31]. They found that after stimulation with PMA alveolar macrophages actually generated more superoxide than did monocytes. Also, by using the chemiluminescence assay, they compared alveolar macrophage and blood monocyte function in patients with lung cancer and found that peak activity of both unstimulated and latex-stimulated alveolar macrophages was higher in the lung cancer group than in the controls [31]. However, in contrast, Chinese workers found that peripheral blood monocytes produced more superoxide when compared with alveolar macrophages in lung cancer patients. In contrast to earlier studies, we assessed the function of macrophages collected from the diseased and disease-free lobes of the same subject separately to evaluate if these cells behave differentially within the same system. Inherent superoxide and hydrogen peroxide production in macrophages was assayed, as was that stimulated with PMA. AMs from patients with nonmalignant lung diseases were also studied. Our results showed that the production of superoxide anion in vitro was significantly higher in AMs from the malignant lobe than in those from the disease-free lobe of lung cancer patients and than in those from patients with nonmalignant lung diseases. The basal levels of hydrogen peroxide in AMs from the malignant and disease-free lobe of lung cancer patients were higher than the level in the cells from patients with other nonmalignant diseases. Therefore, on stimulation with PMA the relative increase (\%) was greater for the cells from the other nonmalignant disease-affected lungs than for those from the malignant or disease-free lobes.

AMs are normally present in the respiratory tract, being particularly abundant in the alveolar spaces [32], and there is a great number of alveolar macrophages in the early destroyed regions in centrilobular emphysema [33]. This suggests the pathologic significance of AMs in the lung parenchyma. Taking into account that AMs stay for a relatively long period inside the lungs, the pathologic significance of the alveolar macrophage is dependent on several endogenous and exogenous factors. The mechanisms of in vivo activation are still ill defined, but mediators such as IL-1, gamma-IFN, and tumor necrosis factor are likely to be implicated. Cytokines can also prime or preactivate alveolar macrophages, thereby increasing the responsiveness of the cell to other stimuli. Among these stimuli, PMA is a potent inducer of $\mathrm{O}_{2}{ }^{-}$and $\mathrm{H}_{2} \mathrm{O}_{2}$ release by alveolar macrophages in vitro. Since PMA is a well-known activator of protein kinase $\mathrm{C}$, the greater activation of 
protein kinase $\mathrm{C}$ by PMA in the macrophages obtained from the malignant lobe, where inflammation is very common, to stimulate the respiratory burst cannot be ruled out. In spite of the fact that activated macrophages have tumoricidal and microbicidal activity, the enhanced levels of reactive oxygen species in the malignant lobe of cancer patients may suggest that the enhancement to the observed levels may not be sufficient to kill the tumor cells; rather these radicals may start acting as tumor promoters.

\section{REFERENCES}

1. Loeb, L.A., Ernster, V.L., Warner, K.E., Abbotts, J., and Laszio, J. (1984): Smoking and lung cancer: An overview. Cancer Res., 44, 5940-5948.

2. Harris, E.D., Jr. (1990): Rheumatoid arthritis, pathophysiology and implications for therapy. N. Engl. J. Med., 322, 1277-1289.

3. Fridovich, I. (1978): Biology of oxygen radicals. Science, 20, 875-880.

4. Babior, B.M. (1978): Oxygen dependent microbial killing by phagocytes. N. Engl. J. Med., 298, 659-668.

5. Sachs, T.C., Maldow, C.F., Craddock, P.R., Bowers, J.K., and Jacobs, H.S. (1978): Oxygen radical mediated endothelial cell damage by complement stimulated granulocytes: An in vitro model of immune vascular damage. J. Clin. Invest., 61, 1161-1167.

6. Lynch, R.E., and Fridovich, I. (1978): Effects of superoxide on the erythrocyte membrane. J. Biol. Chem., 253, 1838-1845.

7. Hafeman, D.O., and Lucas, Z.J. (1979): Polymorphonuclear leukocyte mediated antibody dependent cellular cytotoxicity against tumor cells: Dependence on oxygen and respiratory burst. J. Immunol., 123, 55-62.

8. Ludwig, P.W., and Hoidal, J.R. (1982): Alterations in leukocyte oxidative metabolism in cigarette smokers. Am. Rev. Respir. Dis., 126, 977-980.

9. Hoidal, J.R., Fox, R.B., Lenarhe, P.A., Perri, R., and Repine, J.E. (1981): Altered oxidative metabolic responses in vitro of alveolar macrophages from asymptomatic cigarette smokers. Am. Rev. Respir. Dis., 123, 85-89.

10. Dutton, D., and Broden, G. (1985): Indirect induction of a clastogenic effect in epidermal cells by a tumor promoter. Carcinogenesis, 6, 1279-1284.

11. Weitzman, S.A., Weitburg, A.B., Clark, E.P., and Stossel, T.P. (1985): Phagocytes as carcinogens: Malignant transformation produced by human neutrophils. Science, 227, 12311233.

12. Goldstein, B.D., Witz, G., Amoruso, M., Stone, D.S., and Troll, W. (1981): Stimulation of human polymorphonuclear leukocyte superoxide anion radical production by tumor promoters. Cancer Lett., 11, 257-262.

13. Schwarz, M., Peres, G., Kunz, W., Furstenberger, G., Kittstein, W., and Marks, F. (1984): On the role of superoxide anion radicals in skin tumor promotion. Carcinogenesis, 5, 16631670.

14. Bryant, S., Lynch, R., and Hill, H. (1982): Kinetic analysis of superoxide anion radical production by activated and resident murine peritoneal macrophages. Cell. Immunol., 69, $46-58$.

15. Nothan, C.F., and Root, R. (1977): Hydrogen peroxide release from mouse peritoneal macrophages: Dependence on sequential activation and triggering. J. Exp. Med., 146, 16481662.

16. Weinburg, J., and Misunkonis, M. (1983): Phorbol ester induced $\mathrm{H}_{2} \mathrm{O}_{2}$ production by peritoneal macrophages. Cell. Immunol., 80, 405-415.

17. Park, B., Fikrig, S., and Smithwick, H. (1968): Infection and nitroblue tetrazolium reduction 
by neutrophils: A diagnostic act. Lancet, ii, 532-534.

18. Pick, E., and Keisari, Y. (1980): A simple colorimetric method for the measurement of $\mathrm{H}_{2} \mathrm{O}_{2}$ produced by cells in culture. J. Immunol. Methods, 38, 161-170.

19. Lowry, O.H., Rosebrough, N.J., Farr, A.N., and Randall, R.J. (1951): Protein measurement with Folin phenol reagent. J. Biol. Chem., 193, 265-275.

20. Goldstein, B.D., Witz, G., Amoruso, M.A., Stone, D.S., and Troll, W. (1982): Stimulation of human polymorphonuclear leukocyte superoxide anion radical production by tumor promoters. Cancer Lett., 11, 257-262.

21. Schwarz, M., Peres, G., Kunz, W., Furstenberger, G., Kittstein, W., and Marks, F. (1984): The role of superoxide anion radicals in skin tumor promotion. Carcinogenesis, 5, 16631670.

22. Ohkawa, Y., Iwata, K., Shibuya, H., and Fujita, H. (1984): A rapid simple screening method for screening skin tumor promoters using mouse peritoneal macrophages in vitro. Cancer Lett., 21, 253-260.

23. Lewis, J.G., Hamilton, T., and Adans, D.O. (1986): The effect of macrophage development on the release of oxygen intermediates and lipid peroxidation products and their ability to induce oxidative DNA damage in mammalian cells. Carcinogenesis, 7, 813-818.

24. Nishizuka, Y. (1984): The role of protein kinase $C$ in cell surface signal transduction and tumor promotion. Nature, 308, 693-699.

25. Ashendel, C.L. (1985): The phorbol ester receptor: A phospholipid regulated protein kinase. Biochim. Biophys. Acta, 822, 219-242.

26. Sharkey, N.A., Leach, K.L., and Blumberg, P.M. (1984): Competitive inhibition by diacylglycerol of specific phorbol ester binding. Proc. Natl. Acad. Sci. U.S.A., 81, 607-610.

27. McPhail, L.C., Clayton, C.C., and Shyderman, R. (1984): A potential second messenger role for unsaturated fatty acids: Activation of $\mathrm{Ca}^{2+}$ dependent protein kinase. Science, 224, 622625.

28. Cox, J.A., Jeng, J.A., Sharkey, N.A., Blumberg, P.M., and Tauber, A.I. (1985): Activation of human neutrophil nicotinamide adenine dinucleotide phosphate (NADPH) oxidase by protein kinase C. J. Clin. Invest., 76, 1932-1938.

29. Gerard, C., McPhail, L.C., Marfat, A., Gerard, N.P., Bass, D.A., and McCall, C.E. (1986): Role of protein kinases in stimulation by human polymorphonuclear leukocyte oxidative metabolism by various agonists. J. Clin. Invest., 77, 61-65.

30. Balazowuch, K.J., Snolen, J.E., and Boxer, L.A. (1986): $\mathrm{Ca}^{2+}$ and phospholipid dependent protein kinase $\mathrm{C}$ activity is not necessarily required for secretion by human neutrophils. Blood, 68, 810-817.

31. Weissler, J.C., Lem, V., Lipscomb, M.F., and Toews, G.B. (1983): Chemiluminescence of alveolar macrophages and monocytes in patients with bronchogenic carcinoma. Clin. Res., 31, 859-864.

32. Hoking, W.G., Lassale, P., Fortin, P.L.F., Aerts, C., Bart, F., Fournier, E., and Voisis, C. (1990): Superoxide anion generation by alveolar inflammatory cells in simple pneumoconiosis and in progressive massive fibrosis of non-smoking coal workers. Am. Rev. Respir. Dis., 141, 129-133.

33. Niewoehner, D.E., Kleinerman, J., and Rice, D.B. (1974): Pathologic changes in the peripheral airways of young cigarette smokers. N. Engl. J. Med., 291, 755-780. 